\title{
Constructivism and ICTs to Improve Language Skills ${ }^{1}$
}

\author{
Sonia Rodríguez Salazar ${ }^{2}$
}

Universidad Nacional, Costa Rica

\section{RESUMEN}

Se examina la experiencia de los estudiantes y los profesores de dos grupos de un curso de Elocución con el uso de las Tecnologías de la Información y la Comunicación (TICs), para mejorar sus habilidades de expresión oral en inglés. Se presenta el diseño del curso y la metodología en la cual se fundamentó, así como las apreciaciones de los trabajos de estos alumnos a la hora de mejorar las habilidades comunicativas orales por medio del enfoque constructivista. Se incluyen recomendaciones para poner en práctica esta metodología.

\section{Abstract}

A description is provided here of the experience of the students and teachers of two Elocution courses in which Information and Communication Technologies (ICTs) were used to improve oral communication skills in English. Reference is made to the design of the course and the methodology it is based on, together with some insights of the assignments that students did to improve their English speaking skills through the constructivism approach. Recommendations are also provided for others interested in using this type of methodology.

1 Ponencia presentada en el I Congreso Internacional de Lingiiística Aplicada. Ilevado a cabo en octubre de 2007. en el Campus Omar Dengo, de la Universidad Nacional de Costa Rica.

2 Correo electrónico: srodri@una.ac.cr 
Palabras clave: aprendizaje en línea, ambientes virtuales, enseñanzaaprendizaje del inglés, los TIC

Keywords: e-learning, virtual environments, English language teachinglearning, ICTs

\section{Introduction}

In a world of constant change and technology where more and more children are born immersed in the so-called information superhighway, teachers cannot approach students in a way different from the environment in which they are being raised. Even those who have had little contact with technology as students will have to face this reality at a certain point in their lives. Teaching methods should adapt to pupils and not the other way around. This is why it is essential to train English language students to in the use of Information and Communication Technologies (ICTs) to enhance and motivate their learning, and at the same time to improve their performance in the functional use of English at a communication level. It is important for students to feel interested and eager to participate actively by expressing themselves either spontaneously or in a planned way to transmit ideas in the target language by using different strategies. In the virtual class described here, all participants used ICTs to access both professors and classmates efficiently and to express their opinions in different ways in a more relaxed environment. Oral communication classes normally have the usual participants in the traditional classroom, whereas virtual tools are inclusive and those who tend to show little interest get involved equally in the interactive activities. ${ }^{3}$

\footnotetext{
$3 \quad$ Meredith Bricken, "Virtual Reality Learning Environments: Potentials and Challenges," Computer Graphics 25: 3 (July 1991). 30 March 2007, <http:www.hitl.washington.edu/publications/m-90-4/ m-90-4.html>
} 


\section{Constructivism and ICTs}

At this time, virtual environments are of great value for constructivism in education. These environments offer flexibility, motivation, adaptation, creativity, and versatility for the teacher and for the students. ICTs can change the way in which we are used to seeing traditional learning in a developing country like Costa Rica.

Meredith Bricken notes that objectivism and constructivism represent different conceptions about the learning and thinking process. She states that objectivism infers that the function of mental activities is to represent the real world; therefore, the role of education is to help students learn about the world and reproduce its content and structure inside their thoughts. In addition, she says that constructivism requires building our own reality through the execution of perceptible experiences. This reality is inside the mind of every student rather than in the object of our knowledge. Rather than prescribing formulas, constructivists focus on tools and environments to help students decipher the diverse perspectives of the world while they are building their own. ${ }^{4}$

Bricken adds that when providing virtual environments and tools to students. you can learn even more about the teaching-learning process. Likewise, when developing virtual realities, teachers may guide the development of new technology and even have an effect on educational change. Tools in virtual environments encompass all different kinds of learning because they include techniques for different areas with visual. spoken. logical. aural. intrapersonal, interpersonal and even physical skills.

Consequently, the use of constructivism to support the learning process of a second language in a virtual environment may become the best educational tool for teachers. The virtual classroom is still a space for real communication, but it can take place synchronically or

Bricken. 110 . 
asynchronically. It equally allows the interrelation between student and teacher, orstudentand student provided thatconstructivismand cooperative environment is the central axis in the teaching-learning process.

For the pilot project course described here, the activities carried out in the virtual classroom were centered in the use of the target language and consequently, the functional, communicative, and meaningful uses were important. The virtual environment is one that is adapted to pedagogy, and not pedagogy to the virtual environment. When planning a virtual class, a teacher must take care not to upload all the learning material at once in order to prevent a unidirectional relationship between student and contents only, since this type of environment can become cold and discouraging.

One of the prime motivations of this project is based on the target students since they are going to be trained teachers who may use technological tools and constructivist approaches in their future careers.

\section{The Elocution Class}

This elocution class was based on the socio-constructivist approach extracted from the BPL (Based Problem Learning) theory, ${ }^{5}$ causing students discover the functional use of the English language in a significant manner through the problem-solving technique. Students were motivated to think about diverse topics and look for answers to the problems they had found. In general, the main goal was for students to use the English language to approach problems, negotiate, discuss and transmit knowledge in the target language. This methodology also included communicative competences ${ }^{6}$ important for the acquisition

5 Lone Dirckinck-Holmfeld, Diseño de ambientes virtuales de aprendizaje basados en el plan pedagógico orientado al problema (Material del curso Diseño e implementación de cursos virtuales en el marco de la educación virtual, Universidad Nacional, Costa Rica and University of Alborg, Denmark, 2006).

6 Germán Hita Barrenechea, "El enfoque comunicativo. La enseñanza comunicativa de idiomas en Internet. Características de los materiales y propuesta didáctica." Ministerio de Educación y Ciencia de España. 30 May 2007, <http:// www.mec.es/redele/biblioteca/hita/hita_capitulo3.pdf >. 
of a second language: grammatical competence, socio-linguistic competence, discourse competence, strategic competence, and sociocultural competence.

ICTs were used as a mediating tool in the development of second-language skills. The virtual environment was used to technologically support the exchange of knowledge on the topics covered. In that way, a more dynamic, frequent and flexible method of communication could be used to achieve real interaction among the participants. At the same time this motivated students to participate in a more active and different fashion.

\section{The student's role}

The student's role inside the virtual environments is focused on collaboration, flexibility and mutual responsibility. The student must develop teamwork, set goals and try toreach them, he/she is responsible for his/her own learning and should participate with the transmission of knowledge in a reciprocal manner.

Rosmery Hernández, former coordinator of the UNA-Virtual program at the Universidad Nacional believes that students must show the following characteristics:

- Students must do team work to fulfill a common goal.

- Group members set their goals in the short and the long term and periodically check to see if they were reached, as a basis for identifying changes that must be made, if necessary, with the aim of optimizing actions in the future.

- All the students are responsible for doing their part of the work and providing the other group members with the corresponding material for a better understanding of the new information.

- Students must interact. An exchange of information is required, together with arguments and points of view to have feedback among the group members. 
- Students must make proper use of collaborative skills: They should collaborate developing and practicing responsibilities, managing, decision making, communicating and controlling the difficulties presented. ${ }^{?}$

\section{The teacher's role}

The teacher must be an expert in managing collaborative virtual environments in order to become a mediator, guide, assistant, counselor, and motivator. Both expertise and a well-developed academic background are undoubtedly a plus. In addition, the teacher's work includes pedagogical, social, organizational and technical aspects.

\section{Qualitative Evaluation}

In general, diagnostic, formative, and summative assessments were carried out during the semester. A brief review of the type of evaluation used is useful for better understanding of the project. Diagnostic assessment shows tutors the state of students' communicative skills, as a basis for organizing the material according to their specific needs. Formative assessment is used to have a clear picture of the development of new skills acquired by students as well as the number of objectives still to be reached. Summative assessment shows whether the student has acquired the expected learning at the end of the process. ${ }^{8}$

The evaluation had to be balanced between time devoted to virtual and in-class participation: $45 \%$ for the virtual classroom activities and 55\% for in-class participation. Thus, the assessment was as follows: pair assessment (15\%); language usage (in the development of communication techniques) (20\%); individual speech (10\%); virtual participation (30\%); final exam (25\%).

\footnotetext{
7 Rosmery Hernández. Unidad Didáctica: Diseño e implementación de cursos virtuales en el marco de la educación virtual (Universidad Nacional. 2006).

8 Murray Turoff, "Designing a Virtual Classroom." International Journal of Educational Communications 1 (1995) 2/3. 6 August 2007, <http://web.njit.edu/ turoff/Papers/ DesigningVirtualClassroom.html $>$.
} 


\section{The virtual platform: Moodle}

A brief description of the Moodle platform can be found on its web site. Moodle is an alternative to commercial solutions like Blackboard and WebCT and it is freely distributed under the Open Source license. ${ }^{9}$ Moodle's learning environment is based on constructivist pedagogical principles with a modular design, which makes it easy to add content to motivate students. Its creator Martin Dougiamas is an educator and systems engineer whose work is based on social constructivism principles. The concept of social constructivism extends ideas observed in a social group, which constructs a mutual learning, building a culture of sharing contents and meanings in a collaborative fashion. When one is inserted into a culture like this, we are constantly learning the way to become a part of this culture on many levels.

\section{Working with Virtual Tools}

Since the Moodle platform was used only as technological support for the Elocution class due to the oral communicative nature of this course, the use of tools in this environment was limited to five of them, namely the Interactive journal, the Opinion forum, the Assignment, the News forum, and the Questionnaire.

Interactive Journal: This tool was chosen with the aim of having a way to look at and assess how students work outside the traditional classroom. In the first part of the course, once the students had learned the different communication techniques, they were assigned to be developed outside the traditional classroom and put it into practice inside the classroom. The journal was then used by students to ponder over their individual work within the group and the group's participation all together in the construction of knowledge. They expressed their ideas in regards to the development of the out-of-class activities by

Accessed 25 April 2007, <http:www.moodle.org>. 
peer-assessment and reflecting on their own work. Afterwards, they uploaded this information to the platform.

Opinion forum: Forums were carried out at the end of individual speeches. The forum's objective was for the student to react in an active way after the instructor had posted a question to be discussed. Each student had to add his/her opinion even at times before he/she could see or know everyone else's participations. Undoubtedly, if we compare the traditional classroom and the virtual classroom, individual participation was improved, since one of the biggest obstacles in conversational classes is the lack of participation because of the reluctance to talk in front of the group. In the end, the same individuals are the ones who participate all the time. The forum makes an equitable participation in any of the discussions and the most important is that it is real and within the functional use of the language. The student is forced to think and use the language. In every forum, students were asked to summarize, reflect, critique, add extra information and evaluate their classmates' performance after each speech. In this way, each forum was different and at the same time, practice was provided with a variety of techniques for academic interaction and functional uses of the language.

Assignment: The students had to share their material before presenting their speeches using the Assignment tool. This was done in order to facilitate the other students with a better understanding of the topic to be developed. For example, they would upload a glossary with unknown vocabulary, a link to a web page as supporting ideas, or an article introducing the topic. In this way, the "audience" was prepared for the speaking activity beforehand using critical thinking abilities for a more active contribution to the talk.

News forum: The news forum was a communication space between teacher and students, where they could find new activities, messages, or follow-up exercises. This tool was particularly a great example of the respect towards the leaming speeds of each individual, since they could work on the task at their own speed and as many times as required. 
Questionnaire: This tool allowed teachers to assess the learning of theoretical material in a remote way and thus, the time from the regular class was entirely devoted to language practice and comprehension. Though the main objective of the class was to use the language in different communicative environments; to master the communication techniques was essential for the development of the strategies.

\section{Other possible tools}

Teachers can apply this methodology even if they do not have a virtual platform such as Moodle. All of the above techniques can be developed with similar tools such as e-mail accounts, weblogs, public chat rooms, and the World Wide Web itself. Other public platforms such as Dokeos are also available.

CMap Tools was also used. ${ }^{10}$ It is not part of the Moodle platform, but it is of public use. Among the techniques found for the construction of knowledge, CMap Tools facilitates concept mapping to organize and represent the material studied. The link to the downloading page was pasted in the platform but the students can access it by themselves as well. However, the concept map was first taught from scratch on paper so that the pupils could see the process of the mapping rather than manipulating the technological tool first.

Though these tools donot of fer the privacy that a platform would provide, a well-planned course and subsequent lessons make it possible to achieve the same communicative objectives that this methodology seeks to fulfill.

\section{Conclusion}

The Information and Communication Technologies cannot be inserted into the learning process without due care. They need pedagogical and methodological planning which lays the foundations

\footnotetext{
10 CMap tools can be downloaded royalty free from the web site of the Institute for Human and Machine Cognition: <http://cmap.ihmc.us/>.
} 
of their implementation. As mentioned above, technology by itself is not going to improve the teaching-learning process, but evidence does show that these virtual learning environments can enhance students' experiences and motivation. At the same time, construction of knowledge in a collaborative manner is encouraged with cutting-edge tools.

The Elocution course cultivated students' motivation not only to use the English language in an interesting and significant way, but it also showed these future language teachers that collaborative environments contribute to teaching and to the motivation of those involved. 